Article

\title{
Cultural Resilience-The Roles of Cultural Traditions in Sustaining Rural Livelihoods: A Case Study from Rural Kandyan Villages in Central Sri Lanka
}

\author{
Chandima Dilhani Daskon \\ Department of Geography, University of Otago, P.O. Box 56, Dunedin 9054, New Zealand; \\ E-Mails: chandima.daskon@geography.otago.ac.nz; cdaskon@yahoo.com; Tel.: +64-3-479-8772; \\ Fax: +64-3-479-9037
}

Received: 1 March 2010; in revised form: 9 March 2010 / Accepted: 11 March 2010 /

Published: 21 April 2010

\begin{abstract}
The reasons for the significance of cultural values are complex and many advocacy groups have not successfully provided clear explanations for and convincing arguments in favor of prioritizing cultural values in the development processes. The aim of this paper is to examine the roles played by culture in relation to livelihood resilience, posing the question of how cultural traditions might potentially offer alternatives/adaptive strategies, not only to strength livelihood assets of rural communities, but also in generating new opportunities during vulnerabilities caused by economic, social and political changes. Rural Kandyan communities afford us a good example of "cultural resilience”, relying on longstanding cultural traditions for their survival. This paper shows how culture and traditional values strengthen livelihood resilience and argues that while the impulse for change may come from external influences, adaptation comes from within, through dynamics, which are specific to values of the people.
\end{abstract}

Keywords: culture; resilience; rural communities; livelihoods; Kandy; Sri Lanka

\section{Introduction}

"Modern day people condemn these types of industries as outdated and inadequate as a source of income. But most of our families engaged in paramparika karmantha (industries comes across generations) don't want to quit because we respect our family customs and traditional knowledge. Of course, sometimes it is hard to survive relying on these industries when the input costs are raised and, 
there are marketing problems. But, they are for a short time; we would become helpless if we do not adjust to such situations strategically. Apita kohoma hari jeewath wenna puluwan (we can survive anyhow). By doing this industry for generations, our long-term experience helps us to overcome many problems. These skills run in "our blood". Our grandparents equipped us with such wonderful skills and talents. We are capable in doing different things at different time. As long as we can maintain our family industries, we also "protect” the precious cultural traditions in this country".

The above expression was from a villager, who explained the nature of his livelihood and the way he has been using his family customs, traditional knowledge and experiences to handle difficulties in his life. The manner in which he articulated this revealed many aspects of his livelihood and its relationship to cultural traditions. Despite the problems he encounters due to economic instability, he was happy about the traditional occupation that had been handed down from his ancestors. He believed that long-term experiences and knowledge inherited from their paramparika karmantha (industries from across generations) enabled him to persevere during economic vulnerabilities, providing safety nets to adjust to situations strategically. For many rural communities, recognition of and support for the realization of the potential of their own culture and traditional values will be critical in attaining livelihood security and sustainability. People instinctively make the most of their beliefs, norms, customs, traditional knowledge, religion and spiritual elements and other creative sources to meet diverse livelihood objectives. In the context of sustainable livelihoods, it is important to recognize that vulnerability of livelihood is a constant reality for many rural communities [1], and that insecurity is a core dimension of poverty incidence. By promoting the development of effective and sustainable strategies, based on people's own capacities and knowledge, this paper shows how local people can secure their survival strategies and livelihood resilience through their own skills, customs, values and experiences shared through a common culture, and their moral and spiritual systems. Culture is far from being static, and traditional values, and particularly the identity of being in a "traditional family", reinforce livelihood resilience during times when livelihoods have been vulnerable. Cultural values enhance people's ability to be agents of change, and their ability to question, challenge, propose and ultimately bring in new ways of doing things. Thus, the objective of this paper is to demonstrate how culture and traditional values strengthen effective adaptive strategies during livelihood vulnerabilities, and to argue that resilience of rural communities builds within, through dynamics which are specific to their own values, knowledge and experiences. The significance of cultural resilience as an analytical concept in furthering the understanding of the role of cultural context is discussed, specifically considering the dynamics of how people make a living and the various characteristics of complex adaptive strategies. The paper demonstrates the way that cultural traditions provide a multi-purpose adaptive system, not only securing livelihood strategies and individual economic achievements of people, but also nurturing and safeguarding the embedded values of their societies. In this regard, the paper adopts the Sustainable Livelihood Approach (SLA) as a feasible framework to investigate how cultural values are inextricably connected with people's lives and what roles are played by cultural traditions in relation to livelihood resilience. Information presented in this paper is based on data collected in 2007/09 as part of a wider study conducted to explore the role of cultural traditions in the context of achieving sustainable rural livelihoods in rural Kandyan villages, central Sri Lanka. The research was undertaken for the author's doctoral study, in partnership with the University of Otago, New Zealand. 
After an introduction to the research context and methods, the paper presents the analytical framework by discussing culture and SLA. Then, a brief introduction to two key concepts of vulnerability and resilience will be given, followed by an overview of livelihood vulnerability, referring to three rural village communities in the Kandyan region. This overview gives the villagers' perceptions of the economic and political changes that have occurred in the recent past and the influences on their recurrent livelihood activities. How these people adapt their livelihoods to such changes and the way they build livelihood resilience based on their family customs, traditional knowledge and experiences is presented next, by referring mainly to a few descriptive households' biographies and the examples collected from the three village communities. Finally, the paper discusses the significance of cultural values in resisting change or adapting to it-hence, cultural resilience in the context of achieving sustainable livelihood system in a rural setting.

\subsection{Kandyan Region, Villages and Community}

Kandy, which is the cultural capital of Sri Lanka [2], is located in the central highland region some $116 \mathrm{~km}$ from the administrative and political capital, Colombo (Figure 1). Administratively, Kandy District comprises 20 district secretariats (DS), four urban councils and one municipal council. Additionally, there are about 1,188 Gráma Niladhari divisions (GND) and 2,987 villages in the region [3]. Kandy was the centre for Buddhism in Sri Lanka during the 13th and 14th centuries and has remained a significant custodian of Sinhalese-Buddhist nationalism. Historical and cultural significance were key factors in selecting Kandyan villages and communities as the most suitable research locale for this analysis. Kandy was founded as a kingdom in 1592 by King Vimaladharmasuriya I, whose dynasty ended in 1815, when the British captured its last king, Sri Vikrama Rajasinha [2,4]. The capital of the Kandyan kingdom was known as Senkadagalapura, meaning "the city that increases beauty and prosperity" and survived as the capital for over 200 years from 1592-1815.

Arts and crafts form a rich mosaic in the cultural fabric of Kandyan society, and communities engaged in this sector can be categorized as dancers, drummers, builders, painters, jewellery makers (silver, brass, copper and bronze), ivory carvers, wood carvers and carpenters, lac workers, cane and rattan workers, textile weavers and the makers of musical instruments. Forms of artistic expression that have survived in Sinhala society today owe their origin to, or have derived inspiration from, Kandy. In fact, by the end of the 18th century, Kandy had become a distinctive cultural zone, with its own arts, architecture, crafts, dancing and music. Kandy became a key site in the UNESCO “cultural triangle”, the archaeological project in Sri Lanka which also embraces other ancient capitals such as Anuradhapura and Polonnaruwa. In 1988, Kandy was designated a World Cultural Heritage site by UNESCO. 
Figure 1. Location of the Kandy district and the study villages.

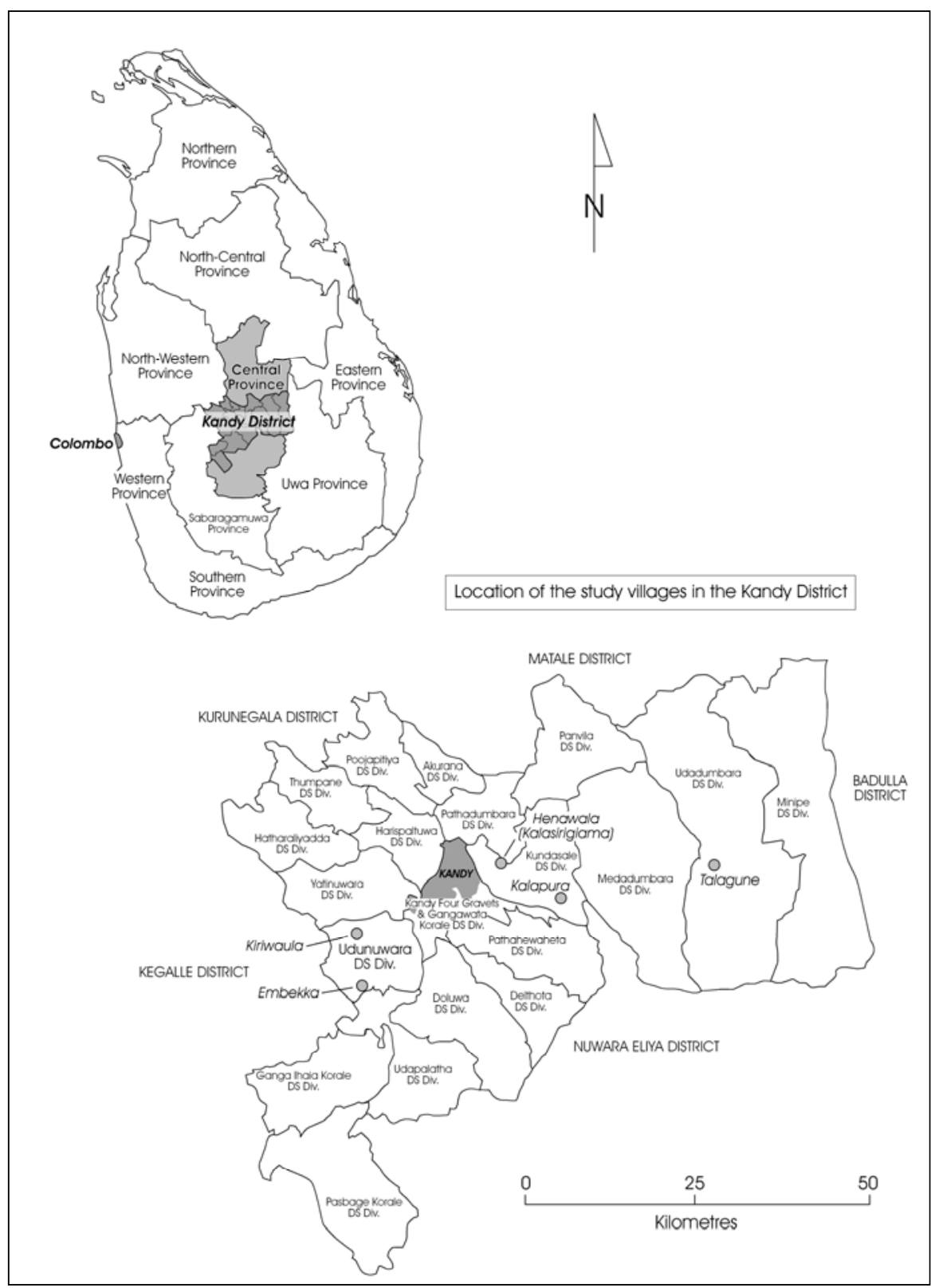

The majority of the Kandyan community descended from an ancient Indian society and its structure was modified by later development [5]. Generally, rural Kandyan communities are considered to be conservative, with a refinement and dignity developed through their hereditary connections, skills and traditional craftsmanship [5,6]. In terms of traditional craftsmanship, they are considered more talented than their Low-Country counterparts who have not so faithfully maintained the ancient craft traditions. During the colonial periods (15th-18th centuries), the country was divided into Up-Country and Low-Country, forming two culturally and politically distinct groups. While the Low-Country has accumulated wealth and power, the Kandyan people have preserved the "traditional ways of living" and retained traditional craft-skills. However, such traditional methods and even institutions are gradually disappearing and, these communities are also facing a crisis and fighting for their survival. Field research was carried out in five villages-Kiriwaula, Embekke, Talagune, Kalapura and Henawela-located in three district secretariats (Figure 1), and the data presented in this paper is based 
on the first three villages. The majority of the village communities engage in traditional handicraft industries such as brassware, silverware and weaving and portray a stronger connectivity between their livelihood and cultural traditions. They belong to two caste groups, namely Goyigama (farmers) and Navadanno (experts in nine traditional industries). As Coomaraswamy describes members of the Navadanno group were held in high esteem, second only to agriculturalists in the economy [5]. The outstanding craftsmen belonging to the Navadanno group worked solely for the royal household and formed a close-knit body of hereditary groups known as the Patal-hatara-“four workshops", namely (i) Abrana pattala — jewellery workshop (ii) Otunna pattala—crown workshop (iii) Rankadu pattala-golden sword workshop (iv) Simhasana pattala-Lion Throne workshop [5,6]. These people took pride in their caste-based professions and ultimately the caste system became a legal recognition of the natural division of society into functional groups. This explains the places automatically assigned by legal and religious sanction in Kandyan village communities. Although these caste divisions or caste-based activities are not functioning in present day Kandyan society, the traditional professions assigned by the caste system are still observable in some parts of these villages. In fact, this connection is much more evident at an event like the Daladá Perahara, (the annual pageant associated with the Temple of the Sacred Tooth Relic). People perform traditional functions at the ceremony, as assigned to their families from the early times. Some outstanding artists still work on projects such as decorating temples, painting religious scenes and even carrying out the construction of religious edifices in their villages.

The study villages are isolated to a significant extent and their social structure portrays their selfsufficiency, strong family relations and ancestral connectivity. They live in peaceful co-operation with one another, according to Buddhist precepts and ancient customs. They have developed cordial relationships with other families, performing the functions and social obligations inherited by their customs and caste. In the homes of wealthy and influential families that are descended from an ancestral craftsman of repute, one can find prestigious heirlooms which speak of the splendid past and the achievements of their Kandyan ancestors. Inherited practices have been preserved among these village communities, by transferring the traditions and skills from father to son and by marrying daughters into families practising the same craft. Fathers also train other suitable young men of the same caste in the craft, along with their sons. Hence, the traditions and knowledge are perpetuated and carried on, undisturbed generation after generation. The data presented in this paper is mainly derived from in-depth interviews (10), key informant interviews (05) and household biographies (02). The majority of respondents were elderly people (both male and female) in the age range of 55-80, often with about 35-40 years of experience in their respective industries.

\section{Culture and Sustainable Rural Livelihoods: Analytical Framework}

Can local cultural values contribute to sustaining rural livelihood systems? How do cultural traditions shape human adaptation? The aim of this section is to examine two key concepts - culture and livelihoods - and the possible connectivity between them. Culture is a highly ambiguous concept that is difficult to define [7], and which is often conceptualized and differentiated according to different contexts. In its simplest sense, culture refers to systems of beliefs, symbols, behaviors, customs, norms, skills, knowledge, and various artifacts, including arts and crafts and a range of 
rituals, ceremonies and religious practices belonging to a particular group, or a society. UNESCO articulates culture as "the total and distinctive way of life of a people or a society" [8]. This is similar to what Verhelst refers to culture as: "every aspect of life; know-how, technical knowledge, customs of food and dress, religion, mentality, values, language symbols, socio-political and economic behaviors, indigenous methods of taking decisions and exercising power, methods of production and economic relations and so on" [9]. Adopting the UNESCO's view, the Commonwealth Foundation interprets culture in its widest sense as, "the whole complex of distinctive spiritual, material, intellectual and emotional features that characterize a society or social group. It includes not only arts and letters, but also modes of life, the fundamental rights of the human being, value systems, traditions and beliefs” [10]. Despite this intricacy, culture in this case is defined in the broadest sense to include traditional values, knowledge, customs and ingenuities, which are both tangible and intangible and which can be preserved, transmitted and invested across generations to improve opportunities, outcomes and sustainability of people's lives.

The concept of livelihood was influenced by early development approaches and established, with growing legitimisation, through several major international forums. For example, the Brundtland Commission in 1987 first introduced 'Sustainable Livelihoods' (SL) as an approach to enhance productivity, ownership and accessibility to resources and income earning activities, ensuring adequate stocks and flows of food and cash to meet 'basic needs' [11]. In 1992, Agenda 21 of the United Nations Conference on Environment and Development (UNCED) expanded the concept by advocating 'sustainable livelihoods for all' as its priority theme. In its simplest sense, livelihood denotes the "means of gaining a living". It also refers to employment and income-generating activities, and seems to be synonymous with, and sometimes overlaps, concepts associated with terms such as employment and work. But, the concept of livelihood describes more complex and diverse strategies for living than what is meant by employment [12]. According to de Haan and Zoomers, livelihood is about individuals, households or groups making a living, attempting to meet their various consumption and economic necessities, coping with uncertainties, and responding to new opportunities [13]. However, Chambers and Conway introduced the concept of "sustainable livelihood" with the following working definition, which became a major source of inspiration to present livelihood research [14]. This idea has partly built upon the concepts of entitlements [15] and capability [16], which are more appropriate for understanding poverty and famine.

A livelihood comprises the capabilities, assets and activities required for a means of living; a livelihood is sustainable when it can cope with and recover from stresses and shocks, and maintain or enhance its capabilities and assets, and provide sustainable livelihood opportunities for the next generation; and which contributes net benefits to other livelihoods at the local and global levels and in the short and long term.

The idea of livelihood offers ways to link socio-economic and ecological aspects into a cohesive policy-relevant structure, and, the concept has being utilized as a tool for understanding the complex nature of poverty and for assessing communities' strengths, weaknesses, opportunities and prevailing threats under different social, economic and political circumstances $[17,18]$. The SLA became popular in terms of assessing poverty situations and providing a set of guiding principles that encapsulate the best way of planning, implementing and evaluating development initiatives at the ground level $[1,19,20]$. However, whilst the SLA is effective in centralising people and their capabilities, it has 
not adequately addressed the significance of a cultural perspective in livelihood analysis [21-26]. An inadequate consideration of the cultural perspective oversimplifies not only people, but also their resourcefulness and capacities and, thus, the complexity and diversity of resource entitlement and livelihood opportunities. Undertaking a detailed study, Daskon and, Daskon and Binns emphasized the significance of a cultural perspective throughout livelihood analysis, and established cultural capital as a new concept “within” livelihood context, where "cultural-traditions” can be explicitly treated as a useful resource in strengthening livelihood sustainability among rural communities [27,28]. The French Sociologist Pierre Bourdieu [29] first introduced the concept of cultural capital, and later on Throsby discussed this concept in detail by referring to economic analysis [30,31]. However in this analysis, cultural capital expands beyond Bourdieu's suggestions and provides a cohesive framework for social inclusion, equality and social security enabling different forms of action and resistance, which are empowering local communities [27]. It is important to be aware that rural livelihoods comprise numerous capabilities and assets that are defined by the local cultural and historical contexts of a particular community. People's values, customs and traditional knowledge systems are constructively used to build and strengthen livelihood assets and to improve their accessibility. In vulnerability situations those values are crucial for reinforcing resilience, by adopting and coping through the use of traditional skills and knowledge passed from generation to generation, which is also vital to the sustainability of rural livelihood systems [27].

\section{Vulnerability versus Resilience}

In the context of livelihood, vulnerability is described as an: exposure to contingencies and stress, and difficulty in coping with them; vulnerability has two sides: an external side of risks, shocks and stress to which an individual is subject; and an internal side which is defencelessness, meaning a lack of means to cope without damaging loss [32].

In this sense, vulnerability is the degree to which a system or unit is likely to experience harm due to exposure to perturbations or stress [33]. In a livelihood context, trends, shocks and seasonality are considered as the major causes of vulnerability and their relative importance in different rural locations is likely to vary. "Trends" can be economic, social or political, and may have fortuitous or adverse effects, whereby livelihoods can be made more or less vulnerable. "Shocks" are events that occur unexpectedly, such as natural disasters, war and civil unrest, episodes of disease or illness, and have widespread impacts on individuals and also on society as a whole. They force people to abandon their basic assets causing adverse impacts on the sustainability of livelihoods. "Seasonal" fluctuations of prices, employment opportunities and food availability are the greatest and most enduring sources of hardship for many people. Vulnerability is also a result of many factors, some of which relate to policies and institutions and a lack of assets. Such factors make peoples' lives more susceptible by increasing or reducing the availability of different resources at different times of the year [33-35].

Resilience is the capacity to absorb sudden changes - the ability to deal with shocks or cope with disturbances, and retain, essentially, the same function, structure, identity and feedbacks [36]. Although, the concept of resilience is widely used in ecology, this paper discusses the concept referring to culture through exploring how cultural traditions contribute to building livelihood resilience and, thus, cultural resilience. When the assets in a livelihood system are depleted and communities are unable to adapt to change, available livelihood strategies become weak, resulting in 
reduced resilience, and vulnerability to disturbance increases. Cultural resilience is vital in achieving rural sustainability and this analysis allows consideration of the extent to which cultural traditions are useful in assuring livelihood resilience. Thus, a vibrant cultural system enables people to pursue robust livelihood strategies that provide, in effect, "layers of resilience" that not only enable people to cope with change, but create the potential to translate adversity into opportunities [25].

\section{Livelihood Vulnerability-Experiences of Changes}

The introduction of liberal economic policies in 1977 was a significant influence in Sri Lankan economic, social and political history. In demonstrating how economic policies and political changes affect village communities and households, this section aims to provide a profile of the villagers' lives. Rural communities are relatively more vulnerable to policy changes [37-39] and they have seriously altered the processes of decision-making, resource exchanging and net-economic returns at individual household levels. The section analyzes the villagers' experiences of livelihood vulnerability, based on the recognition of various trends and shocks that have occurred post-1977, regarded as a period when notable changes occurred in the country's economic and political environments. Figure 2 outlines the prominent changes in economic, governance and political conditions during the 1977-2009 period, coinciding with the periods when political parties were in power. The figure was drawn by referring to secondary information and villagers' classification of the period, based on their experiences of changes in their lives. 
Figure 2. Sri Lankan economic and political changes in the period 1977-2009.

Figure 2: Sri Lankan economic and political changes in the period 1977-2009

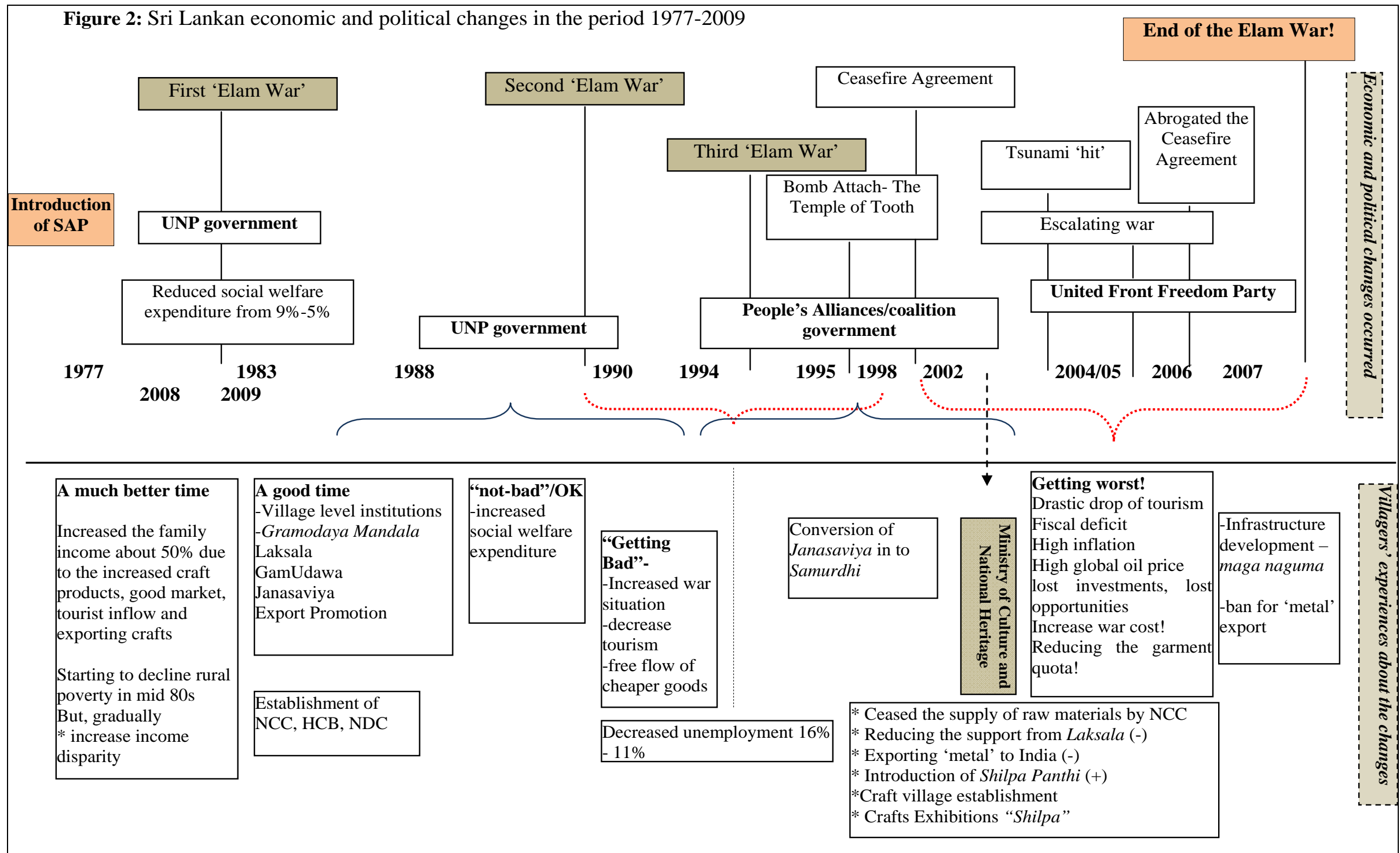


When they considered the impacts of particular changes on their livelihoods, villagers categorized, different times of their lives as godak hoda (much better), hoda (good), tharamak hoda (not-bad), amaru/naraka (difficult/bad), amaruma/hoda naha (most difficult/worst). As the majority of respondents were elderly people, they had a better knowledge and experience of 1977 and after. Changing governance structures and economic policies is frequently a concurrent process and, according to respondents, the experiences were "mixed”, with significant "upturns” and "downturns". The data reveals that economic policy changes are not always negative or cause a vulnerability situation [40], and economic conditions can also move in favorable directions through the implementation of new policy and programs. For example, the immediate policy reforms instituted by the new government in 1977-in particular the open-market, relaxation of trade restrictions, increased raw material supply and a favorable climate for investment and tourism—had significant positive impacts on rural lives and the village craft business. This situation was clearly explained by a villager: "Although the new government was blamed, it was the best time in our lives, because we had no "stress" or uncertainty about this industry. We were almost self-sufficient”. In contrast, in the long term, uncontrollable external trade consequences, the politicizing of government institutional structures, escalating pressures as a result of the unstable global economy, deteriorating national security and local political instability have had significantly negative impacts on rural livelihoods. One respondent clarified this by asserting: "Our industry is becoming "hopeless". Some people have already abandoned and moved to labor work for a daily wage. A flood of cheap Chinese crafts knocked the bottom out of our industry. So, the pressure is always on poor us". The economic liberalization process brought a rapid expansion of the garment industry into rural areas under the 200 Garment Factory Program (GFP). This has caused more unfavorable impacts, particularly on those who rely on the traditional weaving industry, as illustrated by the comments of two villagers from Talagune: "I had 20 machines here; all girls left the industry when the garment factory came to Udadumbera": "Young people are not interested in traditional weaving anymore; garments have absorbed all our young labor”. According to perceptions of the majority of respondents, these impacts have increased sharply in recent years with the setbacks suffered by the tourist industry, because of deteriorating national security, lack of national consensus in policy making and a higher dependency on the global market. More than anything, most of the villagers worried about the escalation of war in the country, which was very unfavorable and unsupportive in terms of securing their traditional livelihoods. An extreme example was recalled by one respondent from Kiriwaula: "We lost our way with the bomb blast at the Maligawa, (the Temple of the Tooth)". This incident, in 1998, was a serious "shock" for many village communities and those whose work was associated with the temple. As mentioned by one elderly man: "We had suffered much during the civil war, but never expected the Maligawa to be targeted". According to another respondent in Embekke: “Tourists are no longer visiting their usual places looking for local crafts. So, to whom are we selling? Laksala and the Kandyan Art Association also reduced their purchases due to insufficient sales". These views illustrated how Kandyan communities had become "secondary victims" of the civil war, with its indirect impact on their traditional livelihoods. Local politicians were also resented for their negligence, and the majority of respondent indicated that traditional crafts and other industries related to the performing arts had become "less interesting" subjects to local politicians. According to one key informant from Kiriwaula: "To improve our traditional livelihoods there must be an interest shown by 
the responsible people of this country. No one is interested in dealing with the Rural Affairs Ministry, because its remunerative package is not attractive”. Government support for these communities and their livelihoods has dwindled to a "zero" point over the years and today these people actually look outside the government sector for their survival. Politicians were criticized for "unequal" treatment, when benefits were provided to only one part of the community, and thus trust in local political elites rapidly deteriorated. However, with the end of war in 2009, there is "new hope” and, as asserted by a villager: "From the blessings of Dalanda hamuduruwo, the miserable war is finished. Hopefully, our lives will shine again”.

The extent of the impact of above changes on individuals and households is determined by each household's ability to respond to particular risks, and, notably, this depends on household assets [40]. Inadequate income has had a considerable effect on the incidence of household stress, livelihood satisfaction and security, all of which are interconnected. One woman in Talagune commented: "We have to think twice about our viyadam (expenses). Our future is very uncertain”. A concern for the majority of respondents was that despite their tireless efforts to earn a living, it is ultimately the middlemen who benefit the most from their trade. This was clarified by a respondent in Kiriwaula: "We are discriminated against by the raw material dealer and again by the wholesale buyers. Buyers ask for a big oil lamp for just 5,000 rupees (\$US 44), which is worth nearly 10,000 rupees (\$US 87). If we argue, we lose the deal; we have no other way”. However, in the interviews conducted among village households it was not possible to form a clear picture of income levels, as the respondents were not straightforward or "open" about their earnings. It appears they have "never" been satisfied with their earnings, and often, they ended discussions about incomes by asserting: "Our life is a misery today. We are jeopardized by the government”. The majority of respondents believed household income had declined continuously, making their lives "hopeless". It is obvious that adjustment measures might be a "shock" for many rural households, due to there being fewer opportunities to increase households' net income at a time when there is removal of subsidies, new wage legislation, devaluations and economic liberalization [41]. However, despite a general "dissatisfaction” among villagers, with respect to income security, according to some opinions, the impact of the liberal policies had been favorable in terms of increased household income, quality of life, and overall satisfaction with livelihoods.

The data about income status and livelihood assets varied according to the experiences of households, and first-hand observations give an impression that these village communities are relatively poor, with less earning capacity, poor quality of life and deteriorating household assets. Indeed, there has been an increased burden on livelihood security and dissatisfaction caused by the exaggerated economic and political pressures of recent times. However, the feature which impressed on many occasions was the apparent lack of economic disparity, with equal standards of living and "better-off" conditions than is normally presumed of many rural communities. Overall, they managed to continue leading a better life, with some "ups and downs", without abandoning the traditional livelihoods that had been inherited through their families. Many of them have also benefited to a reasonable extent from government interventions. Although the qualitative methods employed in the study did not yield a quantitative assessment of particular changes in household incomes and expenditure, the experiences of the majority of villagers indicated that their livelihoods were relatively more secure than those in government sector employment. Nevertheless, the overall experiences of 
policy changes represent the villagers' personal interests in national political elites, as well. Their comments, both negative and positive, were closely associated with the "benefits" and "problems" experienced at different times under different governments and associated policy reforms. Therefore, in this analysis, villagers' responses are used merely to put the nature of their vulnerability in context and indicate how it relates to their respective livelihoods, rather than to provide an in-depth analysis of economic policy changes. Irrespective of the types of livelihood, political interests, economic and social changes, the villagers have sustained their livelihoods under difficult circumstances using their own strategies. The following section looks at this factor in detail.

\subsection{Strategies that Build Livelihood Resilience}

"Living is not easy. We go our own way, [doing] what we have been doing for a long time. We do different things at different times". This was the response of one villager in explaining how he dealt with the above situations. Village communities have responded differently to the economic policy changes, and have built livelihood resilience through mobilizing and managing their livelihood assets in the face of hardship. In relation to livelihood responses, there were some general comments: "We have to live anyhow"; "We know how to handle our livelihoods"; "We do what we know". Many of the responses indicated the diversity and complexity of their capabilities, such that they could meet basic needs and maintain survival portfolios. This leads to an argument for "cultural resilience", reinforcing culture and traditions as a source that enables resistance against livelihood vulnerabilities. The livelihood literature uses broad categories to describe livelihood responses, including coping strategies, which are short term, and adaptive strategies, which are long term [42-45]. As revealed in household responses, villagers have adopted "deliberate" strategies determined by household necessity and choices when households become really "helpless" and "hopeless" about their recurrent survival activities [46,47]. Some of the strategies become "involuntary", in that they involve unintentional activities that are adopted depending on different circumstances and experience. Many of these strategies influenced to a considerable extent by their traditional skills, knowledge and family customs. The following household biographies demonstrate how these people have translated cultural diversity into livelihood opportunities.

\subsection{Household Biography 1-Embekke}

Harishchandra is a craftsman who has been engaged in the brassware industry for more than 40 years. He lives in Embekke with his wife, Soma, and five children. According to them, the economic and political trends that continued from the late 1980s had not significantly impacted on their livelihoods. Overall, the family had remained actively involved in their regular activities most of the time. They had, however, noticed a drastic increase in the cost of labor and brass since 2004, which was seen as the major component of their household expenditure. They had experienced a constant increase in production costs in the late $80 \mathrm{~s}$ and $90 \mathrm{~s}$.

Harishchandra worked regularly from 8 am to 5 pm daily with an additional four laborers. It had cost over 50,000 rupees to finish three pahan (oil lamps), two mal-pochchi (flower vases), a few pathra (bowls) and a few decorative brass ornaments. Relatively, they had a good income from the same products during the late 1990s, as their production costs had been compensated by market profits. 
To reduce input-costs and to maintain their regular income and lifestyle, Harishchandra had mobilized his family labor effectively and efficiently. Earlier, there was no regular participation of family members in this industry, although everyone possessed the skills in brassware. "We all have different strengths. There is no difference between men and women”. But, they had been engaged in different occupations, and deliberately kept a distance from the family industry as it was unnecessary. Today, Soma allocates more of her time to the workshop: "I cook three meals at once and spend more time at the workshop helping my husband”.

The daughters also assist with the work whenever possible: "I do polishing, which is much easier for a woman": "I used to do designing as well, which is really intensive”. Their sons had replaced the "hired-labor" for brass melting, pounding and molding. Now, Harishchandra and his sons regularly work from 8 am to 5 pm, while the others participate from time to time. Compared to 2004, they had reduced input costs by $60 \%$ in 2008 , replacing hired labor with family members. They had minimized the production cost, reduced household expenditure considerably and had achieved a relatively better income in recent years. Therefore, the other increased costs had not drastically altered their regular livelihoods or the quality of their lives, their overall satisfaction and sense of security. "Without our skills and knowledge, we would not have been able to manage the situation. The main additional cost would have been hiring labor, nothing else”.

\subsection{Household Biography 2-Talagune}

As a child growing up in Talagune, Daya was surrounded by weaving as far back as she can remember. Her mother, Dingi-amma, and grandfathers, Rattiya, Rankira and Punchi-Kira, were distinguished weavers credited with preserving many of the traditions of Dumbera weaving. When interviewed, Daya was working in the workshop with her husband, Ariyarathne, and six other weavers. Daya is a mother to two daughters. In 1972, they started Dumbera weaving as a family industry. They expanded the industry in 1982, and in 1994 started the business known as "Daya Weaving" by employing additional labor to operate 20 machines. During the 1989-1994 period, they enjoyed a relative "boom" and, overall, they maintained a "better" life with a good income from their weaving industry. Many of the weaving families in Talagune were badly affected by the garment factories and "abandoned" weaving due to the failure to compete with imported, cheaper textiles: "Some people were on the border between life and death”.

However, Daya's weaving industry had not been affected as, "the imported textiles could be beaten easily by our traditional Dumbera weaving; you'll never replace these traditional pieces”. The resilience of their family industry was driven by their purity, traditional skills and reputation as traditional Dumbera weavers. “Many people started weaving, but they failed. They can't adapt to changing markets, because they don’t have original skills”.

In 2002, Daya and Ariyarathne decided to move towards fashionable cloths, woven by $100 \%$ local cotton with Dumbera-Rata-Dumbera designs: "Today, the fashion industry is interested in hand-made, hand-woven cloths. The traditional designs have become more popular”. However, since 2003, they have had difficult times due to the depression, created by increased costs of living, scarcity of raw materials, lack of tourists, deteriorating government interest and the malfunctioning of Laksala. 
As they had no other way, they replaced cotton yarns with silk yarn in response to the raw material scarcity. Though silk yarn was a little more expensive, they had managed to pay this off with increased demands for their new cloths, woven and designed in colorful and shiny silk yarns. “...it worked better than expected". They mobilized their market by transporting their weaving to Kandy and Colombo in their own vehicle, purchased through a bank loan as they knew their industry had a future demand and they didn't want to give it up. The strategies developed through their own experiences, skills and knowledge reduced livelihood uncertainty by living a "regular" lifestyle. Daya referred to 2007 as the "fortune year", when new hope for their family industry came with a special order from one of the Indian museums to create the Diya-Kachchiy, the waist cloth, which is a traditional cloth with very intricate designs worn by the ancient kings. Their weaving skills and reputation as "traditional weavers" have given them an international exposure, confirming their own strength and providing a “safety net” for the family's survival.

\section{Building Livelihood Resilience through Cultural Values, Customs and Traditional Knowledge}

The household biographies above reveal that Harischandra and Daya have maintained their livelihoods quite reasonably during economic difficulties. Although, there were significant "downturns", their family industries have not been badly affected, as they had managed to reduce input costs and search new markets through effective mobilization of household assets. In Harischandra's case, for example, family labor had been employed where appropriate, reducing the burden of hiring labor. He also received assistance from his extended family, with short-term labor networks and other assets, such as physical and financial capital, used wherever appropriate. "Trial and error" methods and, fortuitously, the persistent reputation of traditional Dumbera weaving helped Daya and Ariyarathne to maintain their livelihood, quite reasonably. In general, these households have acquired a "good" life by increasing the efficiency and productivity of existing livelihood assets. The examples confirm that the skilled and experienced family members are a valuable asset during such difficult times. According to the data, there is no difference in terms of capability between the genders, and every member in these families is equally talented, with particular skills. As revealed from the majority of households, family labor replacement has enabled them to reduce overall input cost by 50 percent, which is a noticeable cost reduction, especially among brass workers. One respondent clarified this by declaring: “Api paramparika minissu ("We are traditional people”). We have "born-talents” and "skilful-hands” [from] practice for generations”. Traditional family entrepreneurship has also given men and women equal opportunities to specialize in different skills by allowing women to join the family industry when needed. Most of the women respondents were comfortable with managing different tasks and responsibilities, both at home and in the workshop: "We have no difficulties "switching” to "craft works' from our regular chores when needed. This industry is not new to us; we have been living with this from the beginning". It was clear that many women interviewed were descendents of the traditional craft families and possessed skills and knowledge of traditional industries, inherited from their families. However, according to the villagers' responses, experiences of livelihood risks and the responses of households varied according to households' characteristics (e.g., size), ancestral relations, level of skills and traditional knowledge, experiences, accessibility to other assets and, in particular, the type of livelihood activity in which they specialized. Although it is 
difficult to comment precisely on whether these households are better-off or worse-off than before, in general they have pursued their regular lifestyles following the changes that have occurred from time to time.

The Kandyan villagers' way of life changes over time, but rather than characterizing it as one marked by dynamic economic and political changes, it can be rather described as displaying a noticeable emphasis on perceived cultural traditions and resistance to external changes. The fundamental feature disclosed by every respondent was that they had "managed" to cope with change through their cultural traditions, much of which denoted an involuntary adaptation to livelihood vulnerabilities. As declared by a key informant: "It is hard to change these people and direct [them] towards new strategies - janmeta vada purudda lokui-(habit is second nature). Since they have been living in their "own world", they don't like to change their attitudes". This statement stresses the importance of the villagers' long-standing socio-cultural systems that include their traditional knowledge, skills, experiences, values, customs and attitudes for their own survival. They have shown their ability to adjust to external stresses and disturbances through their own ways, by using their accumulated knowledge, spiritual and moral values that have obtained for generations. This can be interpreted as a "cultural resilience" which demonstrates an active resistance to unforeseen changes through the protection of their traditional practices. In relation to livelihood analysis, cultural resilience thus refers to communities who collectively or consciously resist change during vulnerable periods by drawing on various livelihood strategies developed through their experiences and knowledge maintained for generations. According to Platteau and Deverenux [44,48], rural communities are always capable in recovering from the effects of shocks and contingencies through their own experiences, skills, knowledge and "trial and error" methods. As shown in the examples, culture acts as a safety-valve for these people by strengthening natural resilience and existing capacities of households' assets, with forward-looking strategies, to endure in the face of unpredictable changes. These adaptations are distinctive as they have not changed the "traditional way of life" of these communities. Thus, cultural traditions are one of the most important factors in helping people realize their potentials, which are largely determined by their surroundings. Sadly, very often these potentials and the "natural strategies" of rural communities are hidden and rather difficult to capture in first-hand observations, and therefore are ignored at the policy level.

The research reveals that the development of secure livelihood strategies is influenced not only by economic and political conditions, but also to a considerable extent by the cultural traditions of the communities. The knowledge acquisition of rural communities is an ongoing, dynamic and natural process that emerges within their traditional institutions. The data reveals that whilst suggesting knowledge of and skill in their industries is their own, references were frequently made to their connectivity to their ancestors as the major source of traditional skills and knowledge. Thus, clearly in terms of quality, there is consensus among the respondents that when considered as a whole, most of their talents/knowledge originated from their grandparents/ancestors. The respondents are more confident and comfortable with their inherited knowledge as a "secure" source and, according to one respondent: "We feel secure and independent, since our knowledge is practical. We know how, when and where our knowledge works well”. These communities possess vast knowledge of and experiences in their enterprises, doing different things at different time, in contrast with people who are better-off than themselves who often rely on one major livelihood [49]. This was particularly noted in their 
intentions to adopt different practices to retain their household livelihoods: "We know what items are demanded at different times of the year. At New Year we have a good market for items like oil lamps, vases, and bowls. In perehara season, ornamental items are in more demand, because there are lots of tourists".

Clearly, villagers regard their traditional knowledge as being very important in strengthening livelihood resilience, and many of the practices they use at present differ little from those used by their predecessors. In some cases, new techniques promoted by government institutions have been rejected in favor of traditional practices. Some cases demonstrated that a household's resilience was a result of personal innovation and experimentation with their knowledge and skills. Although some villagers had tested new techniques, they were not confident, and as one respondent declared: "Better the things we already know than the new things we don't know”. This is not only because new techniques no longer support the retention of their traditional skills, but also there is a problem of affordability. A respondent in Kiriwaula explained his experience, asserting:

When they introduce new techniques, there is a problem of getting new machines and tools; there is no one to help us. They just say "do this and that". If we follow them, we will lose; we have proven that our knowledge and skills are practical and appropriate for any time. They do not know the strength of our traditions, there is no support to keep traditional knowledge, and they just ruin it.

Despite the availability of new techniques, the respondents believed that their livelihoods can only be secured and sustained through their inherited knowledge and, thus direct their efforts towards preserving their inherited values, knowledge and practices. One government official confirmed this by declaring: "Whatever we provide they rely on what they know and received from their paramparawa (generations)". Although "traditions” may change over time, the community consensus decides which elements of their culture are preserved and practised as being paramount. Kandyan villagers' belief in the uniqueness and wealth of their traditional knowledge and techniques is evident in their refusal to adopt new technology for their industries. Because, as clarified by one villager: "New technology does not suit for "traditional works". We used to do all by hand and, it gives them a good quality". Traditional knowledge is part of a complex, multi-purpose system and may not consist of a simple list of technical solutions, or be limited to a series of different applications which vary according to the results obtained. The majority of these villagers, thus, have come to the conclusion that adopting many exogenous strategies would have negative effects on their traditional knowledge and skills and their livelihoods. Therefore, despite growing criticisms of the relevance and applicability of traditional and local knowledge in the development context [50-52], the data reveals the significance and value of traditional knowledge/skills for strengthening livelihood resilience and, thus livelihood sustainability.

Family customs and traditional practices nurtured by these communities through generations of living have helped them to modify/alter their adaptive strategies to accommodate economic fluctuations. In-depth interviews demonstrated that the villagers have established strong social relationships through customs, norms and obligations handed down across generations. As clarified by a village key informant, enduring traditions and cultural practices reinforce the villagers' adaptations to changing situations: "Unlike others, these people are caring and mutually supportive. It is a born quality of these people. They can overcome many problems through their group spirit”. Culture, as we have seen from the previous examples, helps preserve and build strong social capital, which is one of the most valuable assets that people use to combat threats to their livelihood and sustainable well- 
being, building trust, interdependence and participation-often as embedded in what can be called "sustainable culture" or even cultures of sustainability [25]. With good reasoning and logic built on experience, traditional livelihoods provide rules to govern the use of and respect for their resources and obligations when difficulties occur. The sense of rules-in-use and the ancestral connections provide the means by which societies can act on their inherited knowledge and use it to produce their livelihoods based on traditional culture. The data reveals how villagers have used their experience to convert economic “disturbances” into “opportunities” and in this way villagers' responses have taught them to conserve options and opportunities for renewal and novelty [33,53]. Hence, culture must be regarded as vital when considering livelihood resilience. Cultural traditions thrive in society and, in turn, constitute the active, creative and experimental aspects of people. Thus, it should be emphasized that traditions are not merely a custom passively received, but something which is actively entertained with admiration. It is an idea which expresses a value judgment. A certain way of acting is regarded as right; a certain order, arrangement is held desirable. The maintenance of the tradition is the assertion of this judgment [54].

Yet, paradoxically, cultural traditions have not always been effective in strengthening livelihood strategies and household resistance. In some instances, people's traditions have weakened their adaptability during difficult times. Some uncontrollable situations can force people to abandon their inherited industries or move to another source of income. Although they are willing to adopt other sources of income, sometimes they tend to continue their inherited professions as they lack 'other skills' to engage with new jobs. According to some respondents, they remain in the same industry due to their obligations to family traditions, even though it may not fulfill all requirements. In this sense, however, this does not mean that traditional livelihoods are inevitably vulnerable or incompetent activities for human survival; but as explained by one villager in Kiriwaula: "We are capable in making our lives, we have the strength. But we need podi sahayogayak (some support), to make our lives "better" and "easy"." Despite their natural capacities, some villagers anticipate government assistance to retain their traditional livelihoods, especially when they face economic difficulties. Such support and the efficacy of cultural traditions in a society depend on the willingness of the mainstream society to accept traditional knowledge and cultural practices and to accommodate them in a modern social-cultural system. Hence, the introduction of adaptive strategies to local communities may not always be successful, because authorities may give credibility to new strategies only when they are defined in their own context, which may be inadequate in capturing complex values, experiences and the genuine capacities of local people [52]. Thus, the factor that needs to be emphasized is the necessity of seeing the local consequences of any particular economic development within the parameters of local history and aspirations.

Notably, the data reveal that rural communities consciously choose to act in ways that not only increase their livelihood security but also, more importantly, their cultural identities, traditions and value systems. Thus, Kandyan livelihood strategies constitute a form of cultural resilience. In this context, culture is far from being simple and static, and traditional knowledge, ancestral relationships, family customs, rituals, and even the "sense of place"-the Kandyan identity, appear as a strong institution- $\mathrm{a}$ form of organization that reinforces capacities and adaptability in everyday life. Culture is a vibrant resource which enables a community to pursue robust livelihood strategies that are characterized by different "layers of resilience". However, what makes this case unique is that the 
study subjects have been able to direct their successful economic endeavors, not only to promote individual resilience, but also to enhance community resilience and adaptability. Hence, in the rural Kandyan context, cultural traditions provide a multi-purpose "adaptive system” that not only encourages individual economic achievements in a community, but also safeguards the embedded values of their societies.

\section{Conclusions}

This paper aimed to investigate the usefulness of cultural values in building livelihood resilience and how people use their cultural traditions to strengthen livelihood security and sustainability. Respondents were convinced that their knowledge, skills, values, norms and life-long experiences were vital in responding to livelihood vulnerabilities. The findings acknowledge cultural significance in relation to livelihood resilience, and move beyond a negative mentality of culture to apprehend the invaluable role of cultural traditions. Rural communities are knowledgeable and capable of self-reliant organization that displays a thriving livelihood resilience based on ingenuities and intangible values that have been present for generations. Since cultural values are useful in reinforcing livelihood resilience, the Kandyan example challenges the assumption that cultural traditions are "always" an impediment and are rigid structures that fail to negotiate risks, and often retard effective social relations reciprocity and, more importantly, the livelihood choices of people. Culture is a valuable asset that rural communities are already entitled to enabling different forms of action and, provide significant imputes to consider and incorporate cultural perspective seriously into the community development processes.

\section{Acknowledgements}

I would like to thank my supervisors Tony Binns (University of Otago, New Zealand) and Andrew McGregor (Victoria University of Wellington, New Zealand), for their thoughtful comments and critical feedback on this research. I am also grateful to the Otago University Postgraduate Scholarship Committee for their financial support and anonymous reviewers for their constructive comments on an earlier draft of this article. Special thank goes to the Kandyan village communities for devoting their time to participate in this research.

\section{References}

1. Sustainable Livelihoods Guidance Sheet; Department for International Development (DFID): London, UK, 2001; Available online: http://www.ennonline.net/pool/files/ife/section6.pdf (accessed on 12 June 2008).

2. Seneviratne, A. Kandy; Central Cultural Fund, Ministry of Cultural Affairs Sri Lanka: Colombo, Sri Lanka, 1983.

3. Census of Population and Housing-2001 Sri Lanka-KANDY Distric Report; Department of Census and Statistics (DCS): Colombo, Sri Lanka, 2001.

4. Gunasekera, T. Hierarchy and Egalitarianism-Caste, Class and Power in Sinhalese Peasant Society; The Athlone: Landon, UK, 1994. 
5. Coomaraswamy, A. Mediaeval Sinhalese Art, 1st ed.; Pantheon Books: New York, NY, USA, 1956.

6. Thilakasiri, J. Survey Of Traditional Craft Villages and Families Descended from Traditional Craftsmen of Sri Lanka; S. Godage and Brothers: Colombo, Sri Lanka, 1994.

7. Schech, S.; Haggis, J. Culture and Development: A Critical Introduction; Blackwell Publishers: Oxford, UK, 2000.

8. World Cultural Report; UNESCO: Paris, France, 2001.

9. Verhelst, T.G. No Life without Roots: Culture and Development; Zed Press: London, UK, 1990.

10. Putting Culture First: Commonwealth Perspectives on Culture and Development; Commonwealth Foundation: London, UK, 2008.

11. World Comission on Environment and Development (WCED). Our Common Future; Oxford University Press: Oxford, UK, 1987.

12. Arce, A. Value contestation in development interventions: Community development and sustainable livelihood approaches. Community Develop. J. 2003, 38, 199-212.

13. deHaan, L.J.; Zoomers, A. Development geography at the crossrods of livelihood and globalization. Tijdschr. Econ. Soc. Geogr. 2003, 94, 350-362.

14. Chambers, R.; Conway G. Sustainable Rural Livelihoods: Practical Concept for the 21st Century; IDS Discussion Paper 296; Institute of Development Studies (IDS): Brighton, UK, 1991.

15. Sen, A. Poverty and Famines; Clarendon Press: Oxford, UK, 1981.

16. Sen, A. Commodities and Capabilities; Elsevier Science Publishing: New York, NY,USA, 1985.

17. Goldman, I.; Carnegie, J.; Marmo, M.; Munyoro, D.; Kela, N.; Ntonga, S.; Mwale, E. Institutional support for sustainable rural livelihoods in Southern Africa: Framework and methodology. In Natural Resource Perspective; Overseas Development Institute: London, UK, March 2000; No. 49.

18. Goldman, I.; Carnegie, J.; Marmo, M.; Munyoro, D.; Kela, N.; Ntonga, S.; Mwale, E. Institutional support for sustainable rural livelihoods in Southern Africa: Results from Zimbabwe, Zambia, and South Africa. In Natural Resource Perspective; Overseas Development Institute: London, UK, March 2000; No. 50.

19. Carney, D. Implementing the sustainable rural livelihoods approach. In Sustainable Rural Livelihoods. What Contribution Can We Make?; Carney, D., Ed.; Department for International Development (DFID): London, UK, 1998; pp. 3-23.

20. Carney, D. Sustainable Livelihood Approaches-Progress and Possibilities for Change; Department for International Development (DFID): London, UK, 2002.

21. Bebbington, A. Capitals and capabilities: A framework for analysing peasant viability, rural livelihoods and poverty. World Develop. 1999, 27, 2021-2044.

22. Muhia, C.D.K. UHAI, a model for sustainable livelihoods. ILEIA News Letter 2000, 16, 16-17.

23. Adato, M.; Meinzen-Dick, R.S. Assessing the Impact of Agricultural Research on Poverty Using the Sustainable Livelihoods Framework; FCND Discussion Paper 128; International Food Policy Research Institute (IFPRI): Washington, DC, USA, 2002. 
24. Cahn, M. Sustainable livelihood approach. In Proceedings of the 3rd Biennial Conference of the Aotearoa New Zealand International Development Studies Network (DevNet), Massey University, Palmerston North, New Zealand, 5-7 December 2002; Available online: http://www.devnet. org.nz (accessed on 12 August 2009).

25. Glavovic, B.; Scheyvens, R.; Overton, J. Waves of adversity, layers of resilience: Exploring the sustainable livelihoods approach. In Proceedings of the 3rd Biennial Conference of the Aotearoa New Zealand International Development Studies Network (DevNet), Massey University, Palmerston North, New Zealand, 5-7 December 2002; Available online: http://www.devnet. org.nz (accessed on 12 August 2009).

26. Toner, A. Exploring sustainable livelihoods approaches in relation to two interventions in Tanzania. J. Int. Develop. 2003, 15, 771-781.

27. Daskon, C. Culture, Traditions and Sustainable Rural Livelihoods-A Case Study from the Kandyan Villages, Central Sri Lanka; Ph.D. Thesis; Department of Geography, University of Otago: Dunedin, New Zealand, 2009.

28. Daskon, C.; Binns, T. Culture, tradition and sustainable rural livelihoods: Exploring the culture-development interface in Kandy, Sri Lanka. Community Develop. J. 2009, doi:10.1093/cdj/bsp019.

29. Bourdieu, P. The forms of capital. In Handbook of Theory and Research for Sociology of Education; Richardson, J.G., Ed.; Greenwood Press: New York, NY, USA, 1986; pp. 241-258.

30. Throsby, D. Cultural Capital. J. Cultur. Econ. 1999, 23, 3-12.

31. Throsby, D. Economics and Culture; Cambridge University Press: Cambridge, UK, 2000.

32. Chambers, R. Editorial Introduction-Vulnerability, Coping and Policy. IDS Bull. 1989, 20, 1-7.

33. Adger, W.N. Soical and ecological resilience: Are they related? Pro. Hum. Geogr. 2000, 24, 347-364.

34. Alwang, J.; Sigel, P.B.; Jorgensen, S.L. Vulnerability as viewed from different disciplines. In Proceeding of the International Symposium-Sustaining Food Security and Managing Natural Resources in South East Asia: Challenges for the 21st Century, Chiang Mai, Thailand, 8-11 January 2002; Available online: http://www.pik-potsdam.de/research/research-domains/ transdisciplinary-concepts-and-methods/project-archive/favaia/workspace/documents/kavisdocuments/alwangoverview.pdf (accessed on 10 December 2009).

35. Yaro, J.A. Theorizing food insecurity: Building a livelihood vulnerability framework for researching food insecurity. Nor.J. Geogr. 2004, 58, 23-37.

36. Walker, B.; Holling, C.S.; Carpenter, S.R.; Kinzig, A. Resilience, adaptability and transformability in social-ecological system. Ecol. Soc. 2004, 9, 5; Available online: http://www.ecologyandsociety.org/vol9/iss2/art5/ (accessed on 3 June 2009).

37. Reardon, T.; Vosti, S. Links between poverty and environment in developing countries: Asset categories and investment poverty. World Develop. 1995, 23, 1495-1506.

38. Moser, C.O.N. The asset vulnerability framework: Reassessing urban poverty reduction strategies. World Develop. 1998, 26, 1-19.

39. Orr, A.; Mwale, B. Adapting to adjustments-Smallholder livelihood strategies in Southern Malawi. World Develop. 2001, 29, 1325-1343. 
40. Sustainable Livelihood Guidance Sheet; Department For International Development (DFID): London, UK, 1999; Available online: http://www.nssd.net/references/SustLiveli/DFIDapproach. htm\#Guidance (accessed on 12 June 2008).

41. Ahamed, I.; Lipton, M. Impact of Structural Adjustment on Sustainable Rural Livelihoods: Review of Literature-IDS Working Paper 62; Institute of Development Studies (IDS): Brighton, UK, 1997.

42. de Graaf, N.D.; Hendrik, D.F. With a little help from my friends: Social resources as an explanation of occupational status and income in West Germany, The Netherlands and The United States. Soc. Forces. 1988, 67, 452-472.

43. Chambers, R. Poverty and Livelihoods_Whose Reality Count?_IDS Discussion Paper 347; Institute of Development Studies (IDS): Brighton, UK, 1995.

44. Deverenux, S. Livelihood insecurity and social protection: A re-emerging issues in rural development. Dev. Policy Rev. 2001, 19, 507-519.

45. Dercon, S.; Krishnan P. Vulnerability, seasonality and poverty in Ethiopia. J. Develop. Stud. 2000, 36, 25-53.

46. Marschke, M.; Berkes, F. Local level sustainability planning for livelihoods: A Cambodian experience. Int. J. Sust. Dev. World. 2005, 12, 21-33.

47. Marschke, M.J.; Berkes, F. Exploring strategies that build livelihood resilience: A case from Cambodia. Ecol. Soc. 2006, 11, 42; Available online: http://www.ecologyandsociety.org/ vol11/iss1/art42/ (accessed on 5 June 2009).

48. Platteau, J. Mutual insurence as an elusive concept in traditional rural communities. J. Develop. Stud. 1997, 33, 764-796.

49. Chambers, R. Challenging the Professions: Frontiers for Rural Development; International Technology Publications: London, UK, 1998.

50. Agrawal, A. Dismantling the divide between indigenous and scientific knowledge. Dev. Change 1995, 26, 413-439.

51. Agrawal, A. Indigenous and scientific knowledge: Some critical comments. Indigen. Knowl. Dev. Monit. 2004, 3, 3-6.

52. Briggs, J. Indigenous knowledge and development. In The Companion to Development Studies, 2nd ed.; Desai, V., Potter, R.B., Eds.; Hodder Education: London, UK, 2008; pp. 107-111.

53. Berkes, F.; Colding, J.; Folke, C. Rediscovery of traditional ecological knowledge as adaptive management. Ecol. Appl. 2000,10, 1251-1262.

54. Ganguly, S.N. Tradition, Modernity and Development, A Study in Contemporary Indian Society; MacMillan Company of India: Delhi, India, 1977.

(C) 2010 by the authors; licensee MDPI, Basel, Switzerland. This article is an open-access article distributed under the terms and conditions of the Creative Commons Attribution license (http://creativecommons.org/licenses/by/3.0/). 